\title{
Analysis and optimization of idle noise caused by canister purge solenoid valve
}

\author{
Jingjing Chang*, Wei Xiao, Yanlin Chen, Shenghua Qu, Yan Wang, and Xin Ma \\ Dongfeng Motor Company Technology Center, Powertrain Development Department, Wuhan Zip \\ Code 430058 , China
}

Keywords: canister purge solenoid valve, "dada" sound, expansion chamber, idle noise, objective testing, subjective evaluation.

\begin{abstract}
In the development process of a certain CHINA VI proprietary brand car model, there exists the problem of intermittent "dada" sound in the cockpit during idling. After investigation, it's determined that the air pulse noise generated when the canister purge solenoid valve is working, it is transmitted to the car panels through the pipeline, and then to the cockpit, which would cause a "dada" sound. By adding expansion chamber in the desorption pipe and designing part of the pipeline which fixed in the clamp as rubber pipe, the intensity of air pulse can be effectively reduced and the transmission path of air pulse vibration can be blocked. Through objective testing and subjective evaluation, the scheme can greatly reduce the idle noise of the cockpit, thus improving the NVH performance of the vehicle and bringing comfortable riding environment to the passengers.
\end{abstract}

\section{Introduction}

With the emergence of environmental pollution problems, the domestic and foreign requirements for vehicle emissions are increasingly stringent. "Limits and measurement methods for emissions from light-duty vehicles (China 6)" regulations, require that all registered vehicles and vehicles in sale shall meet China 6 since July 1, 2020 [1]. In emission of pollutants from vehicles, oil and gas emissions account for 20\% [2]. Taking into account more stringent testing conditions and procedures, the requirements for control of fuel evaporation emissions of China 6 are at least $80 \%$ higher than China 5 requires [3]. In order to meet the requirements for evaporation emissions of China 6 , the fuel evaporation control system needs to be upgraded accordingly. The volume of the carbon tank increases to 2-3 times of the original, and the diameter of the fuel desorption pipe is thickened, resulting in the increase of the desorption flow of the carbon tank, thus the carbon tank solenoid valve opens and closes frequently for a long time when vehicle is idling. The working noise of the carbon tank solenoid valve will be transmitted to the cockpit, causing intermittent "rattle" sound in the car, bringing uncomfortable experience to drivers and passengers.

This paper focuses on the effective solution to idle "rattle" noise in the cockpit, mainly studying the mechanism and transmission path of working noise of carbon tank solenoid

\footnotetext{
* Corresponding author: changjingj@dfmc.com.cn
} 
valve, the root cause of idle "rattle" noise in the cockpit, and the solution and improvement effect of idle "rattle" noise. By implementing muffling scheme in the fuel desorption pipe and blocking the noise transmission path, the problem of idle "rattle" noise in the cockpit can be effectively solved.

\section{Research on working noise of carbon tank solenoid valve}

\subsection{Working principle of fuel evaporation control system}

Fuel evaporation control system is an important system to control the emission of evaporative pollutants from vehicles, which can prevent the emission of fuel vapor into the atmosphere and pollute the environment. The working principle of the fuel evaporation control system is shown in Figure 1, in which carbon tank and carbon tank solenoid valve are the two main components. The carbon tank absorbs the fuel vapor that evaporates from the fuel tank. When the engine is running, the ECU controls the opening, closing and working time of the carbon tank solenoid valve according to the signals of engine speed, air flow and temperature. When the carbon tank solenoid valve works, the fuel vapor in the carbon tank enters the engine combustion after being mixed with air through the intake manifold, so as to clean the carbon tank.

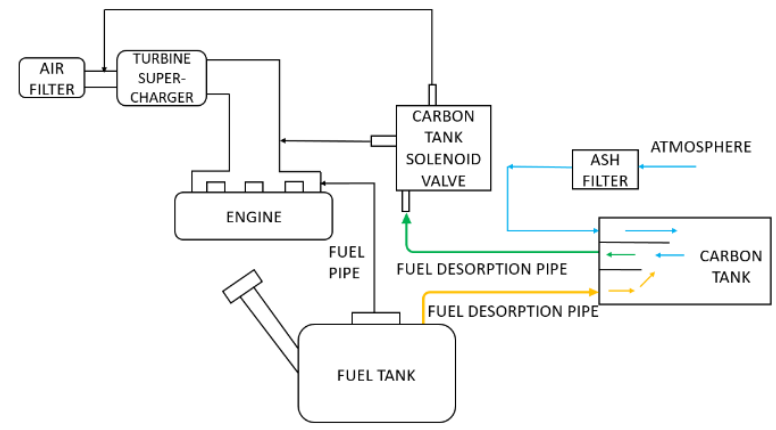

Fig. 1. Schematic diagram of fuel evaporation control system.

\subsection{The working principle and working noise generation mechanism of carbon tank solenoid valve}

The structure of carbon tank solenoid valve is shown in Figure 2, which is composed of solenoid coil, static iron core, moving iron core and valve. When the engine is running, THE ECU uses PWM signal to control the opening and closing of the carbon tank solenoid valve. The electrical signal of ECU is the pulse signal. When the pulse signal is sent out, the moving iron core of the carbon tank solenoid valve does reciprocating movement, collides with the valve port and magnetic plate, resulting in the impact sound, which is generally called the sitting noise of the carbon tank solenoid valve. In order to reduce the impact noise, the impacting part is usually made of rubber. When the carbon tank solenoid valve is without power, the electromagnetic suction disappears. Under the spring force, the moving iron core resets to the position in which the valve port is closed. 


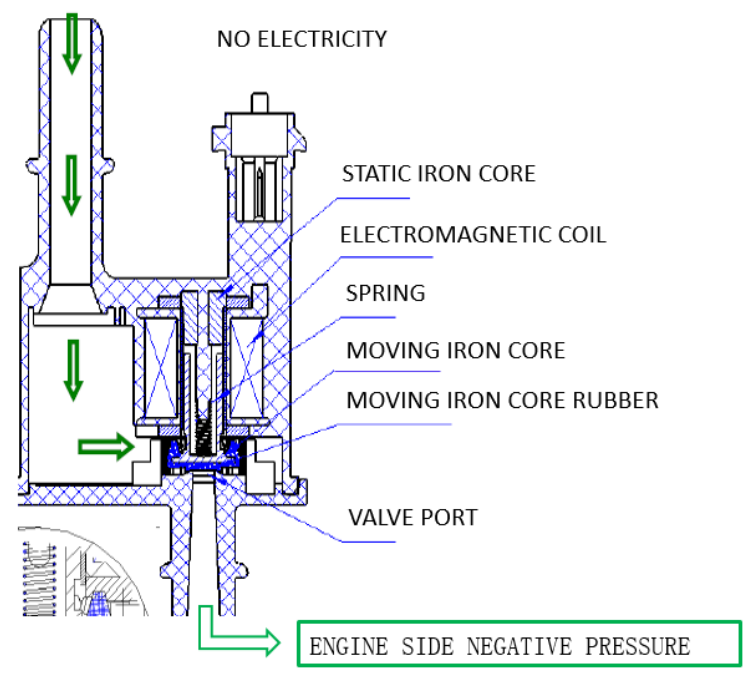

Fig. 2. Schematic diagram of carbon tank solenoid valve.

The fuel desorption pipe is connected to the engine intake manifold through the carbon tank solenoid valve, and relies on the negative pressure of the intake manifold to suck the oil and gas molecules from the carbon tank into the engine for combustion. A certain opening and closing frequency of the carbon tank solenoid valve leads to the impulse of air flow pressure in the fuel desorption pipe, which impinges on the wall of the pipe, thus forming the impulse noise of gas flow.

Generally speaking, the working noise of the carbon tank solenoid valve is composed of the seated noise of the carbon tank solenoid valve body and the impulse noise of gas flow in the fuel desorption pipe. Under the control strategy of most motor companies, the opening degree of carbon tank solenoid valve will change. The electronic control system adjusts the current of carbon tank solenoid valve to make it have the appropriate opening degree. Some electronic control system can make the opening degree of carbon tank solenoid valve between $0 \%-100 \%$ [4]. When the opening degree of carbon tank solenoid valve is not the same, the performance of its working noise will be different. According to the test data, when the opening degree of carbon tank solenoid valve is very small (such as $<5 \%$ ) or very large (such as $>95 \%$ ), the working noise is small. In other range of opening degree, the working noise of carbon tank solenoid valve increases with the opening degree.

\section{Problem investigation and cause analysis}

\subsection{Problem investigation}

In the development process of a certain China 6 independent brand car, the intermittent "rattle" sound is found in the cockpit through subjective evaluation, in the condition that the car is in $\mathrm{N}$ idle speed, the engine speed is $850 \mathrm{r} / \mathrm{min}$, and the air conditioner is off. When the vehicle is running, the speed and engine speed both increase, thus the "rattle" sound is not very prominent due to the cover of background noise such as wind noise, tire noise and engine noise. Therefore, it is necessary to investigate the source of the "rattle" sound when the vehicle is idle and the air conditioner is off.

After opening the cabin cover and looking for the noise source, it is found that the noise comes from the place near the carbon tank solenoid valve. The "rattle" sound usually lasts 
for 10-20 seconds and then disappears for a period of time, but the time of disappearance is not regular, sometimes a few seconds, sometimes a minute or two.

The carbon tank solenoid valve is connected with the power-supply connector of the engine wiring harness. The carbon tank solenoid valve will stop working after disconnecting the connector. When the power-supply connector is disconnected, it is found that the "rattle" sound in the cockpit and near the cabin disappears. If the connector is plugged in again, the "rattle" sound will reappear. When putting hand on the pipe near the carbon tank solenoid valve, the pulse vibration of the air flow can be felt clearly, and the vibration frequency is consistent with the "rattle" sound. When the "rattle" sound disappears, so does the pulse vibration of the tube. Based on the above phenomena, it is determined that the "rattle" sound in the cockpit when idling is caused by the working noise of the carbon tank solenoid valve.

\subsection{Transmission path of carbon tank solenoid valve working noise}

The three elements of noise pollution are noise source, transmission path and receiver. Generally, three methods are used to control noise pollution, such as controlling noise source, blocking transmission path and protecting receiver. Firstly, the noise source is tested and studied.

In order to know the working noise level of the carbon tank solenoid valve, noise tests were carried out on ten samples. The distance between the microphone and the solenoid valve is defined $1 \mathrm{~m}$ (simulating the position of human ear). During the testing, the working parameters of the carbon tank solenoid valve are defined as the working voltage of $12 \mathrm{~V}$, the duty ratio of $50 \%$ and the working frequency of $10 \mathrm{~Hz}$. The test results show that the working noise of ten carbon tank solenoid valve is all less than $40 \mathrm{~dB}(\mathrm{~A})$, which meet the corresponding standard limit. In addition, this carbon tank solenoid valve has been used on other China 5 cars and competitive brands car, and there is no noise problem complaint. Therefore, optimizing the noise source is not the solution to improve the idle noise. Methods to protect recipients (drivers and passengers) are impractical in practice. Therefore, the transmission path is needed to analyze to find effective ways to improve the cockpit idle noise.

The transmission path of working noise of carbon tank solenoid valve is shown in Figure 3 , which is divided into radiation transmission path and structure transmission path [5].

The sound insulation of carbon tank solenoid valve and car body can be used to block the radiation transmission path. The cabin has been soundproofed already. After wrapping the carbon tank solenoid valve with acoustic insulation foam with a thickness of $5 \mathrm{~mm}$ and a density of $400 \mathrm{~kg} / \mathrm{m}^{3}$, the subjective evaluation of idle noise in the cockpit was carried out again. After the evaluation of several vehicles, it is concluded that the improvement effect of idle noise is not obvious, and intermittent "rattle" sound still exists. It can be concluded that the contribution of carbon tank solenoid valve working noise through the radiation transfer path is relatively small.

In the structural transfer path, the position and fixed mode of carbon tank solenoid valve body are firstly checked. The carbon tank solenoid valve is fixed on the engine through a small bracket to avoid direct placement on the car body. Meanwhile, the part of carbon tank solenoid valve which is fixed on the bracket is designed with rubber cushion, which has vibration isolation effect. For further verification, when the carbon tank solenoid valve is separated from the fixed bracket, the "rattle" sound during idling can still be heard in the cockpit. This indicates that the positioning and fixed mode of the carbon tank solenoid valve is not the root cause of the "rattle" sound during idling. The contribution of noise through the transmission path of fixed bracket-engine-suspension system-body sheet plate and cockpit is relatively small. 
Next, the structure transmission path of the fuel desorption pipe needs to be investigated. The fuel desorption pipe is made of hard nylon, connecting the carbon tank with the carbon tank solenoid valve. The first fixed point of the fuel desorption pipe in the engine room is fixed on the suspension through the hard plastic pipe clamp 1, and the second fixed point is fixed on the body sheet plate through the hard plastic pipe clamp 2. In order to verify the possibility of the structure transmission path of the pipe, the fuel desorption pipe can be disconnected from the fixed points of the car body to evaluate whether the idle noise in the cockpit can be improved. After the pipe is removed from the plastic pipe clamp 1, and the plastic pipe clamp 2 is separated from the body sheet plate, it is found that the "rattle" sound during idling in the cockpit basically disappears, and the subjective evaluation is acceptable. This shows that the working noise of carbon tank solenoid valve is mainly transmitted through the structural transmission path of carbon tank solenoid valve - nylon tube suspension system - body sheet plate - cockpit.

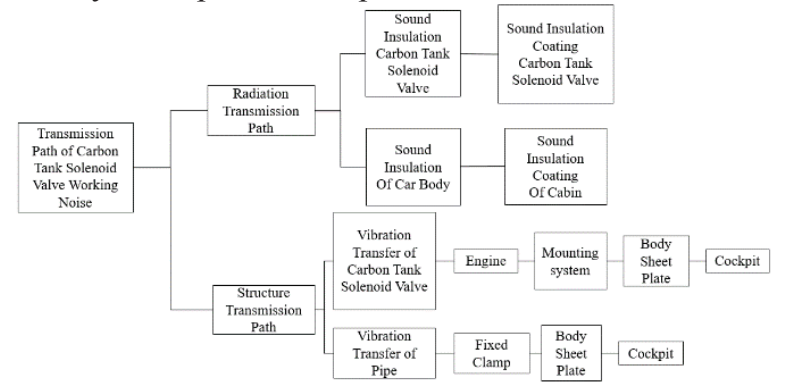

Fig. 3. Transmission path of working noise of carbon tank solenoid valve.

\section{Improvement measures}

"Rattle" sound during idling in the cockpit can be improved in a variety of directions. Since the vibration of nylon pipe is transmitted to the car body through the plastic pipe clamp, the most direct improvement method is to develop the vibration isolation measure of the pipe clamp. The pipe clamp can be developed as a vibration isolation pipe clamp with rubber cushion. Literature [6] introduces the comparison results of subjective evaluation of carbon tank solenoid valve noise in cockpit before and after replacing the vibration isolation pipe clamp, as well as the comparison results of vibration of body sheet plate near the pipe clamp. The results show that replacing two vibration isolation clamps can significantly reduce the noise of the carbon tank solenoid valve in the cockpit, and the vibration isolation clamps can attenuate $50 \%$ of the vibration energy transferred by the nylon tubes. This article will introduce the solution of "rattle" sound during idling in the cockpit from another direction.

Since the electrical signal given by ECU to the carbon tank solenoid valve is pulse signal, impulse air flow vibration will generate inside the fuel desorption pipe at a certain opening and closing frequency, thus causing air flow noise. In order to understand the noise level and main contribution frequency in the cockpit, the idle noise of the cockpit is objectively measured. The measured state is the normal working state of the carbon tank solenoid valve and the non-working state of the carbon tank solenoid valve. The spectrum diagram of cockpit idle noise before and after the carbon tank solenoid valve disconnects the control line is shown in Figure 4. It can be concluded from Figure 4 that the total sound pressure level of cockpit idle noise is $39.7 \mathrm{~dB}(\mathrm{~A})$, and the main contribution frequency is about $280 \mathrm{~Hz}$, which belongs to low-frequency noise. When the carbon tank solenoid valve control line is disconnected, the peak noise disappears and the total sound pressure level drops to 37.84 $\mathrm{dB}(\mathrm{A})$. 


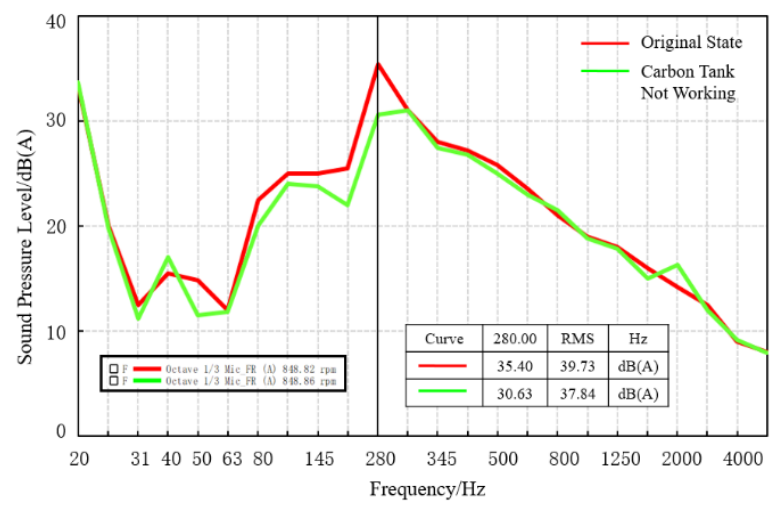

Fig. 4. Spectrum diagram of cockpit idle noise before and after the carbon tank solenoid valve disconnects the control line.

In order to eliminate the peak noise, we consider adding a single expansion chamber muffler in the fuel desorption pipe to transform the pulse flow in the pipe into steady flow. Muffler can allow the air flow through, and also has the function of attenuation or obstruction of sound propagation, is an important device to solve the air flow dynamic noise. The single expansion chamber muffler is one of the resistant silencers. Its muffler principle is to control the acoustic reactance, instead of using the muffler material. It makes use of the acoustic impedance change in the pipe caused by cross-sectional area mutation to generate reflection and interference to achieve the purpose of noise elimination [7].

The single expansion chamber muffler is composed of two mutated cross section pipes connected in reverse. As shown in FIG. 5, the cross-sectional area of the pipe is defined as $\mathrm{S} 1$, and the cross-sectional area of the dilated part of the pipe is S2, so the expansion ratio of the expansion chamber is $\mathrm{m}=\mathrm{S} 2 / \mathrm{S} 1$. The muffler frequency characteristic of the expansion chamber is related to the length of the dilated part of the pipe. When the length of the expansion chamber is an odd times of the $1 / 4$ wavelength of the sound wave, the maximum noise reduction can be obtained at the corresponding frequency. The first maximum noise reduction frequency of the expansion chamber is

$$
f_{\text {max }}=\frac{c}{4 L}
$$

$c$ is sound velocity; $\mathrm{L}$ is the length of the expansion chamber.

Since the peak frequency of idle noise occurs at $280 \mathrm{~Hz}$, the noise reduction frequency of the expanding chamber needs to be designed as $280 \mathrm{~Hz}$. According to formula (1), the length of the expanding chamber should be designed as $30 \mathrm{~mm}$.

The noise reduction of expansion chamber $T L$ is related to the expansion ratio $m$, which increases with the expansion ratio $m$. In general, when the expansion ratio is greater than 5 , the muffling effect will be more obvious. The calculation formula when the noise attenuation reaches its maximum value is:

$$
T L_{\text {max }}=10 \lg \left[1+\frac{1}{4}\left(m-\frac{1}{m}\right)^{2}\right]
$$

Therefore, when designing the pipe, on the premise of keeping a certain distance from the surrounding parts and convenient pipe layout, the expansion chamber with large section area of the expansion part can be selected as far as possible to obtain better muffling effect. Finally, size of the expansion chamber is designed as the interior diameter of the expansion chamber is $30 \mathrm{~mm}$, the internal diameter of the expansion chamber joint is $4.5 \mathrm{~mm}$, and the length of the expansion chamber is $30 \mathrm{~mm}$. The expansion ratio can be calculated as 44.4 . The material 
of the expansion chamber is PA12+GF30. The left and right shells are made by injection molding process and connected together by laser welding.

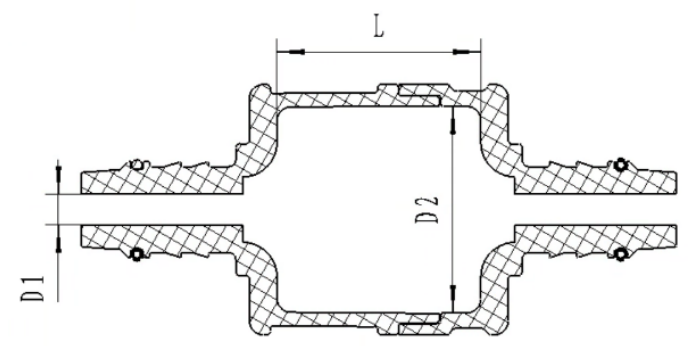

Fig. 5. Structural diagram of a single expansion chamber.

After adding the expansion chamber to the fuel desorption pipe, the idle noise in the cockpit and the rear seat is evaluated subjectively. Due to the influence of desorption flow and other factors, the duty cycle of the carbon tank solenoid valve under idle speed is defined as an unsteady value by the electronic control system, whose value varies between $10 \%$ and $20 \%$, and the corresponding opening degree also varies between $10 \%$ and $20 \%$. The larger the opening degree of the carbon tank solenoid valve, the more obvious the working noise of the carbon tank solenoid valve is. Therefore, before the test, the duty ratio of the carbon tank solenoid valve needs to be fixed at $20 \%$ to ensure that the test is carried out under the most severe conditions. Evaluation results for the idle noise than no expansion chamber scheme improve to some extent, but the "rattle" sound still exists, and will still lead to complaints from drivers and passengers, so the effect is not acceptable.

Since the fuel desorption pipe is made of nylon pipe, which is fixed on the plastic pipe clamp, the contact between the two is still non-vibration isolation. In order to achieve the purpose of vibration reduction, part of the pipe fixed near the pipe clamp is replaced with rubber pipe, and the rubber pipe material is FKM/ECO. After the verification sample is restructured and loaded, the idle noise in the cockpit and the rear seat is subjectively evaluated again. The evaluation result shows that the "rattle" noise when idling is significantly improved, and the working noise of the carbon tank solenoid valve could not be felt in the cockpit and the rear seat, so that the status is acceptable. Under the original state, expansion chamber scheme and expansion chamber + rubber tube scheme, the subjective evaluation results of idle noise in the cockpit and the rear seat are shown in the following table.

Table 1. Subjective evaluation results of idle noise in cockpit and backseat.

\begin{tabular}{c|cccc}
\hline \multirow{2}{*}{ State of Pipe } & \multicolumn{3}{|c}{ Cockpit } & Backseat \\
\cline { 2 - 5 } & Subjective & Noise Level & Subjective & Noise Level \\
Original State & Rating & Rating & Unacceptable \\
Expansion Chamber & 5.5 & Improved & 5.5 & Improved \\
Expansion Chamber & 5.9 & Acceptable & 7.0 & Acceptable \\
+ Rubber Tube & 7.0 & & \\
\hline
\end{tabular}

In order to further verify the effect of the expansion cavity + rubber pipe scheme for fuel desorption pipe, the idle noise under three conditions is measured objectively. The three states are the original pipe state, the carbon tank solenoid valve not working state (disconnect the wire harness joint) and the pipe state with the expansion cavity + rubber pipe scheme. Before the test, the duty ratio of the carbon tank solenoid valve needs to be fixed at $20 \%$ to ensure that the test is carried out under the most severe conditions, and to ensure the consistency of the working state of the carbon tank solenoid valve under the three states. At the same time, during the test, it is necessary to ensure the consistency of microphone and 
sound acquisition equipment in the three states. The test condition of the vehicle is $\mathrm{N}$ idle speed, the air conditioner is off, and the ambient temperature is $30^{\circ} \mathrm{C}$.

Spectrum diagram of idle noise in the cockpit before and after expansion cavity + rubber tube scheme used in the fuel desorption pipe is shown in Figure 6. As can be seen from Figure 6 , the total sound pressure level of the cockpit in the original state is $39.7 \mathrm{~dB}(\mathrm{~A})$, and is $37.8 \mathrm{~dB}(\mathrm{~A})$ when the carbon tank solenoid valve is not working. After the fuel desorption pipe is implemented with the expansion cavity + rubber tube scheme, the total sound pressure level is $37.7 \mathrm{~dB}(\mathrm{~A})$, which is $2 \mathrm{~dB}(\mathrm{~A})$ lower than the original state, reaching the level when the carbon tank solenoid valve is not working.

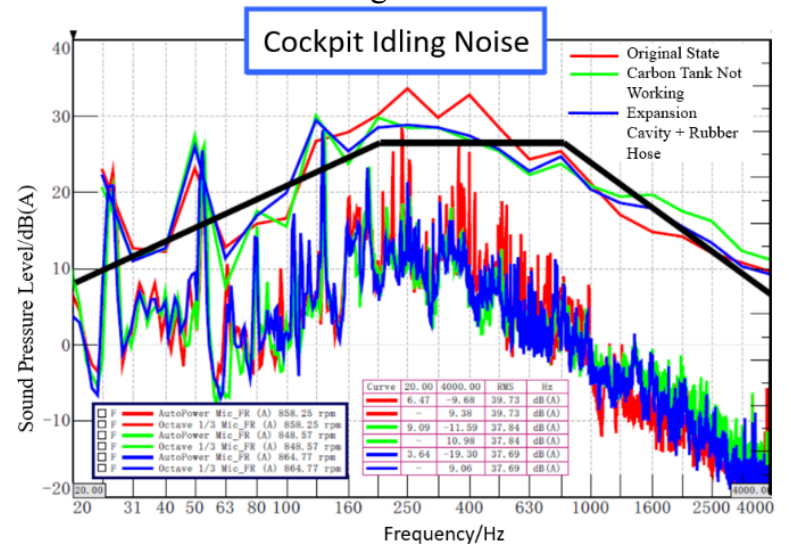

Fig. 6. Spectrum diagram of idle noise before and after the expansion cavity + rubber tube scheme.

Combining subjective evaluation and objective measurement data, it can be concluded that, through adding expansion chamber in the fuel desorption pipe, and change the part of pipe which fixed in the plastic pipe clamp for rubber hose, the air flow impulse intensity can be effectively reduced and the transmission path of air flow impulse vibration can be blocked, so that the purpose of improving the idle noise in the cockpit effectively is achieved. This improving method improves the NVH performance of the vehicle, brings comfortable riding environment to passengers, and avoids customer complaints after the vehicle is put on the market.

\section{Conclusion}

The "rattle" sound during idling in the cockpit which caused by the working noise of the carbon tank solenoid valve, is a common NVH problem in the development of China 6 vehicle. This is the inevitable result of the increase of carbon tank desorption flow of China 6 vehicle, and it is also related to the working characteristics and structure of the carbon tank solenoid valve itself.

This paper mainly studies the transmission path of the working noise of carbon tank solenoid valve, and finally concludes that the root cause of "rattle" sound in the cockpit during idling is that the airflow impulse noise generated by carbon tank solenoid valve is transmitted to the body sheet plate through nylon tube, and finally to the cockpit. The idle noise in the cockpit can be effectively improved by adding the expansion cavity in the fuel desorption pipe and changing the pipe fixed in the clamp to rubber pipe, so as to improve the driving environment. As for the NVH problem caused by working of carbon tank solenoid valve, this paper summarizes the empirical methods for reference in the design of carbon tank solenoid valve and fuel desorption pipe as follows: 
1. Carbon tank solenoid valve should be arranged on the engine as far as possible, to avoid the working vibration transmitted to the body sheet plate;

2. Expansion chamber can be added in the fuel desorption pipeline to transform the pulse airflow in the pipeline into smooth airflow. Under the condition that space allows, the expansion chamber can be arranged as close to the carbon tank solenoid valve as possible to obtain the best muffling effect;

3. The fixation point of fuel desorption pipeline can choose environmental parts not in contact with the body sheet plate, such as the intake system pipeline;

4. The fixed pipe clamp of fuel desorption pipeline can be designed as the vibration isolation pipe clamp with rubber cushion;

5. If the fixed pipe clamp of the fuel desorption pipeline is the hard plastic pipe clamp, the part of the pipe fixed in the pipe clamp can be changed to rubber pipe, which can also play a role in damping vibration.

\section{References}

1. GB 18352.6-2016, Emission limits and measurement methods for light vehicles (China 6) $[\mathrm{S}]$.

2. Shi L. Automotive fuel evaporation emission control system [J]. Automotive Engineer, 2013(1): 50-52.

3. He Y.B, Li C.J, Liu W. Based on the VI regulations of fuel evaporation control system [J]. Automotive Engineer, 2017(2): 56-58.

4. Xue Q.Z. Control mode of automobile gasoline vapor recovery system and fault determination during maintenance. [J]. Electromechanical engineering technology, 2005, 34(7).

5. Pang J, Kan G, He H, Automobile noise and vibration - Theory and application. [M].Beijing: Beijing Institute of Technology Press,2006: 265- 285.

6. Zuo Z.L, Han Q, Ma Y.H, Noise measurement and control of carbon tank solenoid valve in cold environment. [J]. Shanghai Motor, 2015(3) : 24- 27.

7. Chai D.L, Study on hydrodynamics and Acoustic properties of muffled Acoustic structures of vehicle expansion cavities. [D]. Tianjin University, 2005. 